\title{
Possible impact of climate change on apple yield in Northwest China
}

\author{
Meirong $\mathrm{Li}^{1,2}$ (I) $\cdot$ Jianping $\mathrm{Guo}^{3} \cdot$ Jianqiang $\mathrm{He}^{4} \cdot$ Caide $\mathrm{Xu}^{5} \cdot$ Jianke $\mathrm{Li}^{2} \cdot$ Chunrong $\mathrm{Mi}^{6} \cdot$ Sulin Tao ${ }^{1}$
}

Received: 25 December 2018 / Accepted: 29 July 2019/Published online: 10 August 2019

(C) The Author(s) 2019

\begin{abstract}
Apples (Malus pumila Mill.) are widely cultivated in 95 countries and regions around the globe. China is the world's largest producer of apples. Prediction of apple yield in the context of climate change has become an important topic of research. The study sites in this investigation include 28 apple-producing base counties located in the Shaanxi province of the northwest Loess Plateau. In this study, grey relational analysis was used to examine 88 climatic factors and to extract those factors that significantly influence the meteorological yield (MY) of apples. A support vector machine (SVM) was used to make a quantitative prediction of changes in MY in the apple-producing areas of Shaanxi province from the years 2000-2099 under 2 climate change scenarios, RCP 4.5 and RCP 8.5. In addition, fuzzy information granulation was used to analyze the variation trends and variation spaces of MY from 2020 to 2049 and 2050 to 2099, compared with the 1990-2019 reference period. The results showed that for the 10-day and monthly climatic factors affecting the MY of apples, climate resource factors are more influential than meteorological disaster factors and spring factors are significantly more influential than other seasonal factors. Overall, there are more and broader climate resource factors affecting MY, and spring climatic conditions are more important for it. In the RCP 4.5 scenario, 9 base counties showed slight decreases, 2 counties showed significant decreases, 15 counties maintained or had slightly increased, and 2 counties showed significant increases. The variation of unit yield was $-1.44-1.85 \mathrm{t} / \mathrm{ha}$. In the RCP 8.5 scenario, 10 base counties showed slight decreases, 2 counties showed significant decreases, 12 counties maintained or had slightly increased, and 4 counties showed significant increases. The variation of unit yield was $-2.43-2.78 \mathrm{t} / \mathrm{ha}$. For both future climate change scenarios, the uncertainty of MY increased with time.
\end{abstract}

Keywords Apples $\cdot$ Shaanxi $\cdot$ MY $\cdot$ Unityield $\cdot$ Climate change $\cdot$ Support vectormachine $\cdot$ Time window analysis $\cdot$ Grey relational analysis

Copyright: (C) 2018 Li et al.

This is an open access article distributed under the terms of the Creative Commons Attribution License, which permits unrestricted use, distribution, and reproduction in any medium, provided the original author and source are credited.

Electronic supplementary material The online version of this article (https://doi.org/10.1007/s00704-019-02965-y) contains supplementary material, which is available to authorized users.

\section{Jianping Guo \\ gjp@cma.gov.cn \\ Jianqiang He \\ 1764166@qq.com}

1 Nanjing University of Information Science and Technology, Nanjing, Jiangsu, People's Republic of China

2 Shaanxi Early Warning Center, Xi'an, Shaanxi, People's Republic of China
3 Chinese Academy of Meteorological Sciences, Beijing, People's Republic of China

4 Key Laboratory for Agricultural Soil and Water Engineering in Arid Area of Ministry of Education, Northwest A\&F University, Yangling, Shaanxi, People's Republic of China

5 Northwest Air Traffic Management Bureau CAAC, Xi'an, Shaanxi, People's Republic of China

6 Institute of Zoology, Chinese Academy of Sciences, Beijing, People's Republic of China 


\section{Introduction}

Apples (Malus pumila Mill.) are widely cultivated in 95 countries and regions around the world. In 2013, world fruit production was $203,579,000 \mathrm{t}$, of which $82,162,000 \mathrm{t}$ were apples, accounting for $40.4 \%$ of the total. China is the world's largest apple-producing country. In 2014, China produced 40.6 million $t$ of apples, accounting for $48 \%$ of the total world apple production (FAOSTAT 2018).

In China, apple-producing areas can be divided into 4 major apple-growing areas; the northwest Loess Plateau is China's largest and is also a region that has great yield increase potential associated with climate change. The major appleproducing areas in Shaanxi province are located in the northwest Loess Plateau. There are many apple-producing base counties/districts that mainly employ contiguous cultivation. The ecological environments for apple growth are generally consistent within the region and the cultivation area, and yield of the main cultivar, Fuji apples (Malus pumila Mill. cv. Fuji), exceeds $70 \%$, accounting for $29.3 \%$ of the apple cultivation areas in China, translating to an annual yield of 9,880,100 t. The recent total annual value of industrial apple production was 4.079 billion US dollars (Li et al. 2014; National Bureau of Statistics of China 2016).

Precipitation, temperature, and solar radiation are the major climatic factors affecting apple growth and yield $(\mathrm{Pu}$ et al. 2008; Fujisawa and Kobayashi 2011). Changes in meteorological factors can greatly influence annual changes in apple yield ( $\mathrm{Li}$ et al. 2011). Some studies have analyzed the causes of changes in apple yield in China during different years and found that decreased winter temperatures, spring frosts, and high temperatures and aridity in summer and autumn are major meteorological factors limiting the growth of apple trees. This is particularly true during the flowering and maturity stages in the Shaanxi apple cultivation areas (Eccel et al. 2009; Qu et al. 2013). Temporally extrapolating global climate change, it is predicted that the concentrations of greenhouse gases will increase, resulting in elevated temperatures and changes in the spatiotemporal distribution of precipitation. By 2050, China's mean annual temperature is forecast to increase by $2.3-3.3^{\circ} \mathrm{C}$, and by 2100 , the mean annual temperature is projected to increase by $3.9-6{ }^{\circ} \mathrm{C}$. Compared with the 30 -year mean rainfall from 1961 to 1990 , the mean annual rainfall has been predicted to increase by $10-12 \%$ (Ding et al. 2006). Agroforestry is the industry that is the most sensitive to climate change. Northwest China is particularly susceptible to changes in climate and is an ecologically fragile belt (Guo et al. 2006). In the last 50 years, climate warming and drying in this region have been significant, and these changes have already impacted apple yield (Xin et al. 2015).

In order to study the effects of climate change on apple production in China, we must carry out the simulation and prediction of apple growth, development, and yield under different climatic conditions. Conventional crop models clearly describe the process and mechanisms of yield formation. Currently, the EPIC model is being used to study the yield of fruit trees over many years (Zhang et al. 2011). However, there are many parameters used in the EPIC model and these parameters are difficult to obtain. In addition, the spatial scale of this model is at the orchard level, which is smaller than the county-level scale of apple base counties. There have been no reports on the application of fruit tree yield models at larger spatial scales and no fruit tree yield models currently exist that are suitable for application at the spatial scale of this study.

The meteorological estimated yield model is another commonly used prediction method for crop yield. In this method, the statistical relationship between meteorological data and crop yield is established and a statistical model is then constructed by taking additional factors into consideration. Finally, a mathematical model is utilized to derive the crop unit yield prediction. This method divides total crop yield into trend yield, meteorological yield (MY), and random yield. First, historical yield data are used to construct an equation to calculate trend yield. Analysis is then performed to obtain MY. In this method, MY is the annual fluctuation of yield caused by fluctuation of meteorological conditions. Trend yield is a long-cycle yield component that reflects productivity development levels over historical timespans, i.e., technical yield. Random yield is the yield component that is affected by disease, pests, social unrest, and other stochastic factors. Random yield accounts for a small proportion of total crop yield and is usually not considered in actual calculations (Fang 2011; Wan et al. 2016). The MY comprehensively considers the effects of early and mid-late stage meteorological factors that affect fruit yield over a single year. This yield component can better explain yield fluctuations in fruit trees in different years associated with climate resource allocation during different time periods. MY is the most effective component for studying the changes in fruit yield associated with climate change and provides a method for predicting apple yield at a regional scale in China's apple-producing areas as well as in other appleproducing countries. An analysis of major meteorological factors that constituted the MY of fruit trees was the foundation and key for the development of MY estimation model (Xin et al. 2015; Xu et al. 2015).

Apple trees are an important type of economic fruit tree, and their yield is intimately associated with financial gain. Prediction of fruit yield from crops such as apples significantly impacts the economic development of many countries. One example is a research project by Aggelopoulou et al. (2011) in which image analysis was employed to study the flowering distribution and flower density variability in apple orchards in Greece which led to the development of an apple tree analysis algorithm based on image processing. Photographs of trees in full bloom were used to predict yield, with a prediction error of $18 \%$. Papageorgiou et al. (2013) simulated the yield of apple orchards in central Greece and employed dynamic influence graphs to study yield 
classification models for apples. The aforementioned studies were mainly used in the early prediction of apple yield. A shortcoming of this approach is that changes in factors affecting yield during the later stages of apple growth were not considered. In addition, the time series of these studies were relatively short and did not include sufficient quantitative analysis of long-term effects on apple yield. These projects also failed to consider the effects of factors other than flowering quantity on yield.

There have been very few quantitative studies on the effects of elevated carbon dioxide concentrations, higher temperatures, increased rainfall, and changes to other climatic factors associated with climate change on fruit yield in the Loess Plateau (Wan et al. 2016; Xu et al. 2015). A possible reason for this dearth of research may have to do with the fact that the growth and development of crops are influenced by the integrated effects of many environmental factors, and abnormal changes to each environmental factor will ultimately affect yield (Zhai et al. 2005).

However, it is certain that climate change will inevitably have significant effects on apple yield in China's major production areas. Therefore, accurate prediction of the response of apple yield to climate change is a prerequisite for the adaptation of China's apple industry to climate change. To achieve this goal, certain questions need to be addressed. How are the effects of climate change on apple yield and production related to various climatic factors? By 2099, what will be the magnitude of the effects of climate change on apple yield? With respect to apple cultivation in Northwest China, will climate change have mainly positive effects or negative effects? These questions are currently unanswered.

In this study, we carried out the analysis and prediction of variation trends in apple yield in apple-producing areas in Shaanxi province under 2 climate change scenarios, RCP 4.5 and RCP 8.5. Historical apple meteorological data from various counties/districts in Shaanxi province over three decades (19822013) as well as future meteorological data (2020-2099) from regional climate models were utilized. The main aims of this study were as follows: (1) to systematically analyze both the meteorological factors that affect the MY of apples in the base counties of Shaanxi province, as well as the effects of meteorological disasters on apple yield; (2) to construct a predictive model for the MY of apples and major climatic factors in the base counties/districts in the study region; (3) to use meteorological data generated from regional climate models to carry out the prediction of future (2020-2099) variation trends in apple yield for the apple-producing areas of Shaanxi province.

\section{Materials and methods}

\subsection{Study area and meteorological conditions}

Shaanxi's apple-producing areas are mainly located in hills and valleys of China's Loess Plateau (106.5-110.27 $7^{\circ}$, $34.21-36.53^{\circ} \mathrm{N}$, altitude $\left.600-900 \mathrm{~m}\right)$. This region has a semiarid continental monsoon climate. Among these appleproducing areas, the Weibei fruit-producing region (including Xianyang, Tongchuan, Weinan, and Yan'an prefecture-level cities) and the Guanzhong fruit-producing region (mainly located in the city of Baoji) have a total of 28 apple-producing base counties. These areas have comprehensive apple yield and meteorological data series (Li 2013). The annual mean temperatures of these base counties range from 9.2 to $13.8^{\circ} \mathrm{C}$, annual rainfall ranges from 458.3 to $674.7 \mathrm{~mm}$, and annual sunshine hours range from 1883 to $2514 \mathrm{~h}$. The total area of apple orchards in these base counties is approximately $542,000 \mathrm{ha}$, and apple yield is $9.194 \times 10^{6} \mathrm{t}$, accounting for $84 \%$ and $95 \%$ of the apple cultivation area and yield, respectively, for the entire province. Meteorological data were obtained from the Shaanxi Meteorological Data Center and yield data are from the 1980-2015 Shaanxi Statistical Yearbook.

According to climate suitability and the risk of meteorological disasters (Li 2013; Wang 2012), the 28 major appleproducing base counties can be divided into 3 regions (zones I, II, and III) (Fig. 1). Zone I is located in the Beishan region and is the most suitable region for apple trees, zone II is located in the eastern section of the Weibei fruit-producing region, and zone III is located in the western section of the Guanzhong fruit-producing region (Fig. 1).

\subsection{Data collection and processing}

\subsubsection{Climate change data}

The data employed in the study are from the outputs of a simulation conducted by the Abdus Salam International Centre for Theoretical Physics (ICTP) regional climate model version 4 (RegCM4) (Chu Zheng and Zhao 2017). The RegCM4 is driven by the Chinese model of BCC_CSM1.1 which contributed to CMIP5. There is only one realization of BCC_CSM1.1, and it is used to derive the initial and time evolving lateral conditions at 6-hourly intervals needed to drive RegCM4. The RegCM4 domain covers continental China and surrounding areas with a grid spacing of $50 \mathrm{~km}$.

As reported by previous studies (Giorgi et al. 2012; Xin et al. 2013; Zhou et al. 2014a), BCC_CSM1.1 show reasonable performances in reproducing the present day climatology, as well as the time evolution and spatial pattern of the twentieth century warming. The warming projected in the twentyfirst century under RCPs is close to but slightly lower than the multimodel ensemble of CMIP5 models due to its lower climate sensitivity. To be more specific, the global mean warming trend under RCP4.5 and RCP8.5 of it during 2005-2099 are $1.44{ }^{\circ} \mathrm{C} / 95$ year and $3.73{ }^{\circ} \mathrm{C} / 95$ year, with the CMIP5 ensemble as $1.75^{\circ} \mathrm{C} / 95$ year and $4.09{ }^{\circ} \mathrm{C} / 95$ year, respectively. 


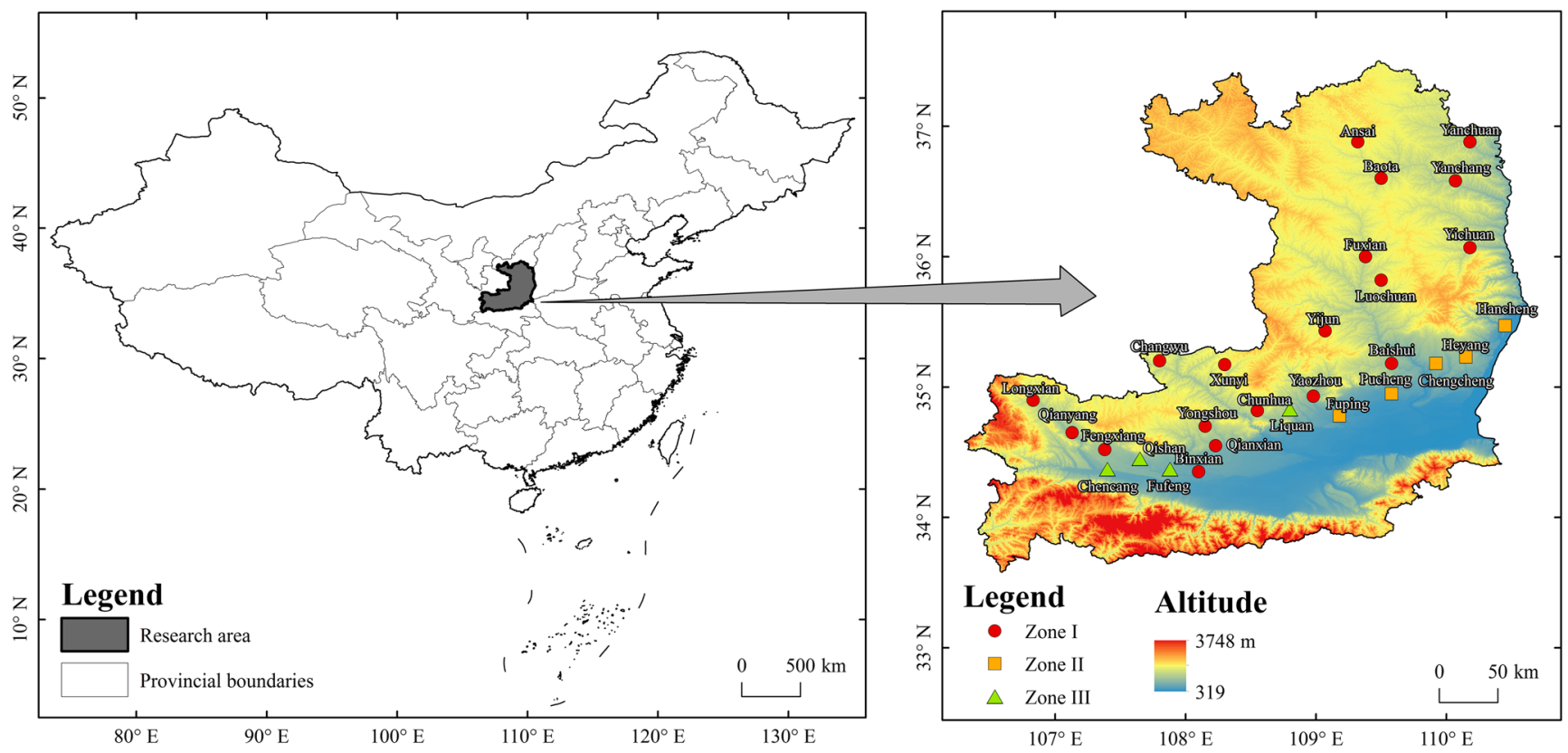

Fig. 1 Apple-producing regions in Shaanxi province. The 28 base counties are divided into 3 main regions: zone 1 (circles, mainly northern fruit-producing areas in Beishan), zone II (squares, mainly

Weibei fruit-producing areas), and zone III (triangles, mainly fruitproducing areas in western Guanzhong)

The RegCM series are among the most commonly used RCMs over East Asia and China (Flato et al. 2013; Gao and Giorgi 2017). RegCM shows good performances in reproducing the present day climate over the region, characterized by the complex topography and unique monsoon climate systems. Furthermore, it may also project a different climate change signal compared to the driving GCMs due to its stronger topographic forcings.

In the simulations, three types of representative concentration pathway (RCP) of RCPrf (reference), RCP4.5, and RCP8.5 were considered, which consider detailed global carbon cycle and dynamic vegetation process. The pathway of RCPrf represents the contemporary scenario with a simulated time series of 1951-2005 and is primarily used for data assimilation. RCP4.5 represents the scenario that balances greenhouse gas emissions and economic development, with the highest priority on development. RCP8.5 stands for the highest pathway for greenhouse gas emissions. Both RCP4.5 and RCP8.5 have a simulated time series of 2006-2099.

Climatic data under the pathways of RCPrf, RCP4.5, and RCP8.5 were used in the study. After bias correction with contemporary scenario data and observations, daily weather data consisted of temperature (mean, maximum, and minimum), rainfall, solar radiation, and wind speed from 1961 to 2100 with a spatial resolution of $0.5^{\circ}$ latitude by $0.5^{\circ}$ longitude.

In this study, climate data were divided into 3 time periods: 1990-2019, 2020-2049, and 2050-2099. The 1990-2019 timespan was selected as the reference period. Two different RCP scenarios (RCP 4.5 and RCP 8.5) with different greenhouse gas (carbon dioxide) emissions were selected. These particular scenarios were selected because they better reflect the current socioeconomic conditions of radiative forcing and emissions. Climate data were used to calculate the regional climate change data in apple-producing areas in Shaanxi province for 140 years. The calculation process consisted of 2 major steps: spatial reduction and temporal expansion. In the first step, inverse distance weighing (IDW) interpolation and linear interpolation were used to interpolate the prediction values for daily climate variables from RCP grid points into the daily values for the 28 base counties in the study area (Guo et al. 2006). Following that, the deviation correction methods for different climate variables at various sites were compared with the contemporary (1961-2005) dataset under the RCP scenarios in order to confirm that the daily data obtained from every site were consistent with observation (Zhang 2005; Zhang 2007). Subsequently, the correction methods for the daily climate variables of the base counties were used for future (2006-2100) climate variable datasets under the RCP 4.5 and RCP 8.5 scenarios. In the second step, all of the climate variables included in the study were compiled into climate variable datasets with varying temporal scales, according to the study requirements. These datasets were primarily 10 -day and monthly, with a minority of annual-scale datasets.

\subsubsection{Calculation of MY}

The trend yield of apples is intimately associated with tree age, irrigation conditions, and technology levels. Trend yield 


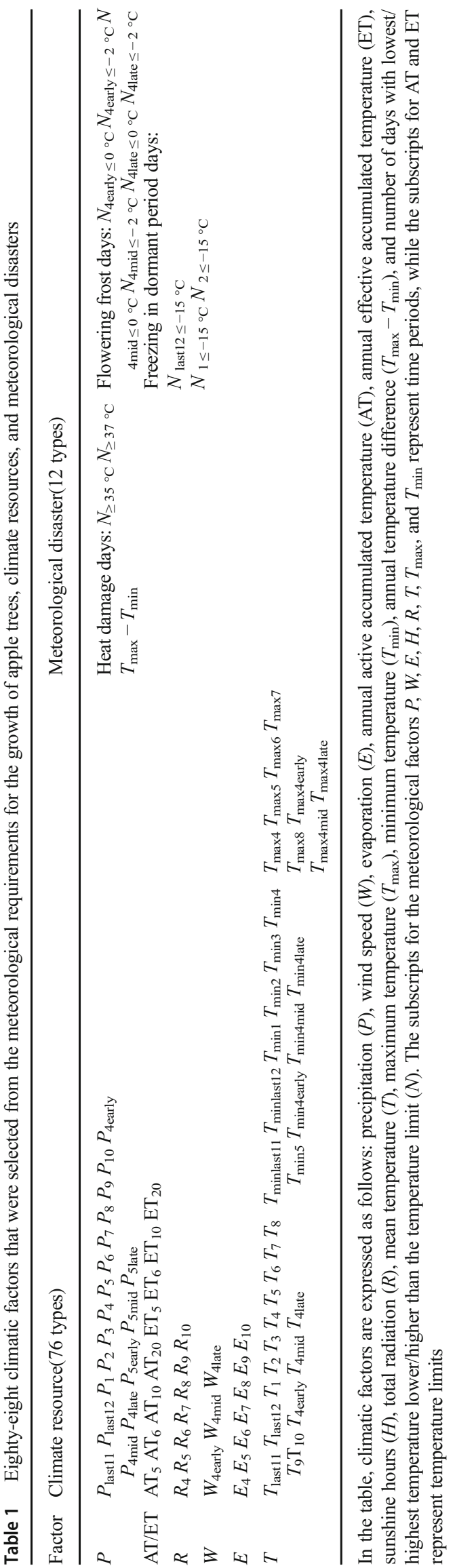

represents the effects of science and technology levels on apple yield. The trend yields of the 28 apple-producing base counties were fitted using 4 different methods, including 5year, 3-year, and 2-year moving averages, as well as quadratic polynomial fitting. The annual MY is the difference between the unit yield and the trend yield for the same year. The MY of the 28 apple-producing base counties were calculated using the aforementioned 4 methods by subtracting the trend yield series from the corresponding unit yield series (Xin et al. 2015; Wan et al. 2016). Following that, a separation method for selecting the lowest standard deviation for the trend yield and unit yield time series of the previously described 4 methods was used to calculate the MY of the base counties in different years. After 2000, the unit yield levels and trend yield levels of apple-producing areas in Shaanxi province have gradually increased. Therefore, our study used the average trend yield in the apple-producing base counties from 2000 to 2009 as a baseline value for the trend yield. Then, the MY that was calculated from the RCP 4.5 and RCP 8.5 scenarios was used to calculate the 2000-2099 unit yield.

\subsection{Analysis of climatic factors}

Given the meteorological requirements for the growth of apple trees, climate resources, and meteorological disasters, we selected 88 salient climatic factors to study. These factors were used in different phenological stages (Table 1), including germination (usually March), pollination (April), young fruit setting and initiation of physiological differentiation of flower buds (May), growth of young fruits (June and July), apple expansion (August and September), harvest (October), and dormancy (December through February of the following year).

This study required the solar radiation data from the base counties. However, long-series solar radiation meteorological observation data were only available for the Baota district of the Shaanxi apple-producing region. Therefore, the observed total solar radiation for that area was compared with theoretical calculation results in order to determine the equation parameters for monthly solar radiation in the apple-producing areas. The total monthly solar radiation data were calculated from astronomical radiation, relative sunshine hours, and radiation parameters in the base counties (Angstrom 1924) (Eq. (1)).

$R_{s}=\left(a_{s}+b_{s} \frac{n}{N}\right) R_{a}$

In this equation, $R_{\mathrm{s}}$ is solar radiation, $n$ is the number of sunshine hours, $N$ is the maximum possible sunshine hours, $n$ / $N$ is the relative sunshine hours, $R_{\mathrm{a}}$ is astronomical radiation, and $a_{\mathrm{s}}$ and $b_{\mathrm{s}}$ are radiation parameters that vary with atmospheric conditions and magnetic declination of the sun (latitude and month). 
Grey relational analysis is a multivariate objective statistical analysis method (Deng 1982, 2002) that is widely used in cross-domain research between meteorology and agriculture (Yang et al. 2017; Zhao et al. 2017; Deng 1985). In this study, we carried out grey relational analysis on the formation factors for MY. Our grey system consisted of the MY of apples in every base county plus the 88 meteorological factors. Every meteorological factor was taken to be a factor in the grey system. Grey T's correlation method was used for comprehensive analysis of the relationship between the meteorological factors and MY (Sun and Dang 2008). During data processing, the annual MY time series in the 28 apple-producing base counties of Shaanxi province from 1980 to 2014 was used as the reference series. The time series from many years of data for the 88 meteorological factors were used as comparison series by county. The weighted average of the correlation coefficients of the time periods was defined as the degree of correlation between 2 time series. In this study, a program to calculate the degree of correlation between MY and climatic factors in the apple-producing base counties was written using MATLAB R2014b (Cao 2007).

\subsection{Prediction methods for MY}

A support vector machine (SVM) is a neural network method that yields outstanding prediction results (Corinna and Vladimir 1995). This method was constructed on the basis of statistical learning theory and structural risk minimization. An SVM obtains the best compromise between complexity (learning precision towards specific training samples) and learning ability (ability to identify any sample without errors) based on limited sample information in order to obtain the best generalization. SVMs exhibit many unique advantages for solving problems with a small number of samples as well as non-linear problems. SVMs can also be used for pattern recognition and in function fitting. The SVM method has already been implemented in many classification and regression prediction studies (Papageorgiou et al. 2013; Wang et al. 2013). In this study, we used the LIBSVM v3.22 software developed by Professor Chin-Jen Lin from National Taiwan University (Sun and Dang 2008) and incorporated a radial basis function kernel (William et al. 2007) to complete program improvements and the calculation of regression predictions in the MATLAB R2014b environment (http://www.csie.ntu.edu.tw/ $\sim$ cjlin/libsvm/).

In this investigation, the annual MY of the stations under the RCP 4.5 and RCP 8.5 scenarios were obtained using SVM prediction for the 10 climatic factors with the highest grey correlations. Here, we used the prediction of MY in an apple-producing base county to describe the usage process of SVM neural networks. The 1982-2013 climatic factor dataset served as the input variable for the training function. The output variable was the MY of the corresponding total yield. The input and output variables were used to construct a regression model. The input variables for the predictive function were the climatic factors from 1991 to 2099 under the RCP 4.5 and RCP 8.5 scenarios. The constructed regression model and input variables were used to predict the output variables, which were the MY under different climate change scenarios. An SVM was used to predict monthly evaporation based on monthly precipitation, mean temperature, and mean wind speed (Feng et al. 2015). For this calculation, monthly precipitation, mean temperature, and mean wind speed were the input variables and monthly evaporation was the output variable.

In this study, we employed an SVM to construct 75 regression prediction models, including 19 evaporation predictions and $56 \mathrm{MY}$ predictions, under the $2 \mathrm{RCP}$ scenarios. Prior to prediction, the input and output variables for the training function and predictive function underwent $[0,1]$ standardization. Following regression prediction, the output variables underwent inverse normalization. Standard deviation and the correlation coefficient for variance were used as indicators of prediction accuracy.

The theory of fuzzy information granulation (TFIG) was established on the basis of fuzzy logic and information granulation, with an essential mathematical underpinning (Zadeh 1979, 1997, 1998). In order to analyze the variation trends and variation spaces of minimum values, mean values, and maximum values of MY for the base counties at different timepoints, we divided the yield series into 3 periods: 1990-2019 (the reference period), 2020-2049, and 2050-2099. The time window data for the different time periods were used for fuzzification. The fuzzy information granulation method (Zadeh 1997) was employed to differentiate the quantitative prediction results for MY from the 3 time periods into prediction intervals in order to carry out the prediction of the MY variation space for each time period. During the calculation, 3 years was taken as the time window unit. The program call and calculation were completed in the MATLAB R2014b environment.

\subsection{Model calibration and assessment}

Bilinear interpolation was used on the RCP 4.5 and RCP 8.5 meteorological data. After the grid data were corrected for the site data of the base counties, error correction was carried out for the climatic factors of every base county in order to eliminate the systematic errors that are present in climate model simulation results (Zhou et al. 2014b). An SVM was used on the corrected 1982-2013 climatic factors from the base counties under the RCP 4.5 and RCP 8.5 scenarios to predict MY and correction was carried out using either Eq. (2) or (3).

$$
\begin{aligned}
Z_{i} & =X_{i}+\left(\frac{\sum Y_{j}-\sum X_{j}}{n}\right) i=1982,1983, \ldots 2099 ; j \\
& =1982,1983, \ldots 2013
\end{aligned}
$$


$Z_{i}=X_{\times} \frac{\sum Y_{j}}{\sum X_{j}} \quad i=1982,1983, \ldots 2099 ; j=1982,1983, \ldots 2013$

In these equations, $Z_{i}, X_{i}$, and $Y_{j}$ are the meteorological yields that were corrected, predicted, and calculated using yield separation methods, respectively.

The correlation coefficient, standard deviation, and model efficiency $(E$; Eq. (4)) between the corrected value and the MY that was calculated using yield separation methods for the same period were used in order to assess the reliability of the prediction results. For the same base county, the same method was used for the correction of predicted value from 2014 to 2099.

$$
E=1-\frac{\sum\left(Y_{j}-Z_{j}\right)^{2}}{\sum\left(Y_{j}-Y\right)^{2}} \quad j=1982,1983, \ldots 2013
$$

In this equation, $Y$ is the mean MY for 1982-2013. When an SVM is used to predict monthly evaporation from the evaporating dish, $Y_{j}$ is the observed value, $X_{i}$ is the predicted value, $Z_{i}$ is the corrected value, and $Y$ is the observed mean. The correction method and model efficiency are the same as those used for the MY. Usually, the smaller the standard deviation, the lower the error between 2 column values. When $E \geq 0$, the corrected predicted value will be better than the mean value that was differentiated from the unit yield. When $E$ approaches 1 , the accuracy of the predicted value is extremely high.

\section{Results}

\subsection{Annual changes in MY}

During the period 1983-2012, the MY of apples from the base counties in Shaanxi province ranged from -2.6 to $3.5 \mathrm{t} / \mathrm{ha}$, accounting for -46.1 to $39.3 \%$ of the unit yield. The standard deviations of the entire Shaanxi province, as well as the individual yields of zones I, II, and III during the 30-year period were $0.4,0.33,0.99$, and 1.16 , respectively (Fig. 2). During the three decades from 1983 to 2012, there were 11 years with positive values in Shaanxi province and the 3 zones; 1997 was the only year with a negative value. Annual changes in yield from 1997 to 2017 were the most significant. The number of years with value less than 0 was greatest in zone III, followed by zone II, and then zone I. Since the annual changes in MY for the 3 main apple-producing areas in some years were not synchronous, the annual changes in total MY of apples in the entire province were relatively stable.

\subsection{Major climatic factors that affect the MY of apples in the base counties}

Grey relational analysis between MY and the climatic factors for the 28 base counties in Shaanxi province showed that the

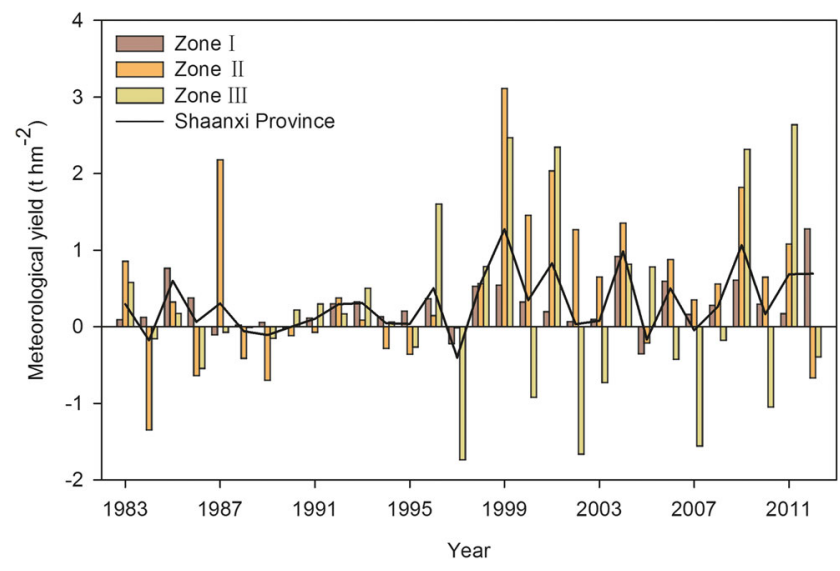

Fig. $2 \mathrm{MY}$ of apples in the entire Shaanxi province, as well as the individual zones I, II, and III, from 1983 to 2012

frequency of the summer climatic factors was significantly higher than the frequencies of the other 3 seasons (Table 2). Among the climatic factors that affect MY, the frequency of meteorological disasters was relatively low. In addition, the factors affecting MY varied from one apple-producing area to another. In the table, $T_{2}$ is a major factor affecting all 3 apple-producing zones, while $T_{\max 4}$ and $T_{10}$ mainly affect zones I and III, and $E_{4}$ only affects zone I.

\subsection{Future changes in the MY of Shaanxi apple-producing areas}

\subsubsection{SVM model calibration and validation}

The SVM model calibration and validation results demonstrated that the mean standard deviation for the predicted values in the corrected evaporation model was 10.4 and the model efficiency was 0.81 . Since the constructed model reasonably reproduced evaporation dynamics and trends, the calculated evaporation values from the RCP 4.5 and RCP 8.5 scenarios can be used as input variables for the prediction of apple yield. Under the RCP 4.5 and RCP 8.5 scenarios, the regression slope of the predicted MY values after correction and separated values in 26 of the 28 base counties approached 1 and the mean correlation coefficient was 0.94 . The standard deviation ranged from 0.22 to $3.5 \mathrm{t} / \mathrm{ha}$, with a mean of $1.1 \mathrm{t} / \mathrm{ha}$. Under the RCP 4.5 scenario, $E$ ranged between -0.667 and 1.0 , with a mean of 0.82 . This indicates that the model can explain $82 \%$ of the prediction results. Under the RCP 8.5 scenario, $E$ ranged between -0.421 and 1.0 , with a mean of 0.84 . This indicates that the model can explain $84 \%$ of prediction results.

\subsubsection{Spatiotemporal variation trends in the MY}

From 2000 to 2099 under the RCP 4.5 climate change scenario, the MY in Ansai, Luochuan, Binxian, Yongshou, Chunhua, Yaozhou, Qianxian, and Jijun (zone I) and Fufeng 
Table 2 Climatic factors for the 28 base counties in Shaanxi province that are consistent with MY (1982-2013). In the table, the correlation relationships between climatic factors were determined using variance tests

\begin{tabular}{|c|c|c|c|c|c|c|c|c|c|c|}
\hline Base county & Factor1 & Factor2 & Factor3 & Factor4 & Factor5 & Factor6 & Factor7 & Factor8 & Factor9 & Factor10 \\
\hline Ansai & $W_{4 \mathrm{mid}}$ & $P_{5}$ & $P_{9}$ & $N_{1 \leq-15{ }^{\circ} \mathrm{C}}$ & $T_{6}$ & $T_{10}$ & $P_{7}$ & $T_{\min 4 \mathrm{mid}}$ & $P_{3}$ & $P_{10}$ \\
\hline Baota & $R_{4}$ & $T_{10}$ & $T_{2}$ & $E_{4}$ & $T_{1}$ & $\mathrm{AT}_{20}$ & $T_{\max 4}$ & $P_{7}$ & $T_{\text {min4late }}$ & $T_{\text {last11 }}$ \\
\hline Yanchuan & $W_{\text {4late }}$ & $T_{3}$ & $T_{1}$ & $E_{10}$ & $R_{10}$ & $T_{\max 6}$ & $E_{4}$ & $T_{\max 5}$ & $P_{6}$ & $P_{7}$ \\
\hline Yanchang & $N_{1 \leq-15{ }^{\circ} \mathrm{C}}$ & $\mathrm{AT}_{6}$ & $T_{4}$ & $P_{1}$ & $\mathrm{AT}_{20}$ & $W_{4 \mathrm{mid}}$ & $T_{4 \text { late }}$ & $W_{\text {4late }}$ & $R_{4}$ & $N_{4 \text { early } \leq 0{ }^{\circ} \mathrm{C}}$ \\
\hline Yichuan & $P_{6}$ & $R_{10}$ & $T_{\max 4}$ & $E_{10}$ & $P_{5 \text { mid }}$ & $T_{\max 4 l a t e}$ & $W_{4 \text { early }}$ & $T_{\text {max4early }}$ & $T_{10}$ & $T_{4 \text { early }}$ \\
\hline Changwu & $T_{10}$ & $P_{5 \text { mid }}$ & $T_{2}$ & $P_{8}$ & $P_{5}$ & $T_{\text {max4early }}$ & $T_{\max 6}$ & $\mathrm{AT}_{10}$ & $T_{\text {min4late }}$ & $T_{\min 5}$ \\
\hline Fuxian & $R_{6}$ & $T_{\max 7}$ & $P_{\text {last11 }}$ & $R_{9}$ & $T_{4 \text { early }}$ & $T_{\min 4 \mathrm{mid}}$ & $N_{\geq 35^{\circ} \mathrm{C}}$ & $T_{\min 2}$ & $P_{4 \text { mid }}$ & $P_{5 \text { early }}$ \\
\hline Xunyi & $T_{8}$ & $T_{4 \text { early }}$ & $T_{7}$ & $E_{7}$ & $T_{\max 7}$ & $T_{1}$ & $\mathrm{AT}_{20}$ & $T_{\text {max4early }}$ & $T_{\min 2}$ & $E \mathrm{~T}_{10}$ \\
\hline Baishui & $P_{1}$ & $T_{10}$ & $T_{\min 4 \text { late }}$ & $T_{2}$ & $P_{2}$ & $T_{\max 4}$ & $P_{\text {4late }}$ & $T_{\min 2}$ & $P_{5 \text { early }}$ & $T_{\text {max4late }}$ \\
\hline Luochuan & $T_{\max 5}$ & $T_{\max 8}$ & $W_{4 \mathrm{mid}}$ & $E_{6}$ & $\mathrm{AT}_{10}$ & $P_{6}$ & $P_{5 \text { early }}$ & $P_{\text {5late }}$ & $T_{\max 4 \mathrm{mid}}$ & $P_{\text {4late }}$ \\
\hline Yijun & $T_{\max 4}$ & $T_{\text {max4late }}$ & $P_{2}$ & $T_{\max 6}$ & $T_{2}$ & $P_{5 \text { early }}$ & $E_{4}$ & $T_{\min 2}$ & $T_{\text {min4late }}$ & $T_{\text {4late }}$ \\
\hline Pucheng & $P_{4 \text { mid }}$ & $E_{7}$ & $P_{\text {5late }}$ & $P_{4}$ & $T_{\max 5}$ & $\mathrm{AT}_{10}$ & $\mathrm{AT}_{20}$ & $W_{\text {4late }}$ & $T_{4}$ & $P_{3}$ \\
\hline Chengcheng & $W_{\text {4late }}$ & $W_{4 \text { early }}$ & $T_{\max }-T_{\min }$ & $P_{3}$ & $T_{\max 6}$ & $T_{\max 4 \operatorname{mid}}$ & $P_{\text {last11 }}$ & $P_{\text {5late }}$ & $W_{4 \text { mid }}$ & $P_{2}$ \\
\hline Heyang & $T_{2}$ & $W_{\text {4late }}$ & $T_{\max 6}$ & $P_{\text {5late }}$ & $P_{5}$ & $P_{\text {4late }}$ & $T_{1}$ & $E_{6}$ & $P_{5 \mathrm{mid}}$ & $N_{\geq 35^{\circ} \mathrm{C}}$ \\
\hline Hancheng & $T_{3}$ & $T_{\text {last12 }}$ & $T_{2}$ & $T_{10}$ & $T_{\text {max4late }}$ & $T_{\max 6}$ & $P_{5 \text { mid }}$ & $T_{\min 2}$ & $E_{5}$ & $E_{8}$ \\
\hline Longxian & $T_{\max }-T_{\min }$ & $T_{\text {4late }}$ & $P_{8}$ & $W_{4 \text { mid }}$ & $T_{\text {minlast11 }}$ & $E_{4}$ & $T_{\max 7}$ & $P_{1}$ & $T_{\max 6}$ & $P_{\text {last12 }}$ \\
\hline Chencang & $P_{4 \mathrm{mid}}$ & $T_{9}$ & $P_{8}$ & $T_{1}$ & $P_{\text {last12 }}$ & $T_{7}$ & $T_{\text {max4early }}$ & $T_{2}$ & $T_{10}$ & $W_{4 \text { early }}$ \\
\hline Qianyang & $P_{5 \text { early }}$ & $T_{\min 4}$ & $T_{\max 4}$ & $T_{4 \text { late }}$ & $E_{4}$ & $T_{\text {max4late }}$ & $T_{\max 4 \mathrm{mid}}$ & $P_{8}$ & $R_{9}$ & $P_{5}$ \\
\hline Binxian & $T_{2}$ & $T_{10}$ & $W_{4 \mathrm{mid}}$ & $T_{\max }-T_{\min }$ & $P_{2}$ & $R_{4}$ & $T_{\max 4}$ & $P_{\text {last12 }}$ & $T_{\min 2}$ & $T_{\text {max4late }}$ \\
\hline Qishan & $T_{\text {last12 }}$ & $T_{\max 4 \mathrm{mid}}$ & $P_{7}$ & $T_{10}$ & $T_{4 \mathrm{mid}}$ & $T_{4 \text { late }}$ & $E_{7}$ & $T_{\max 4}$ & $\mathrm{AT}_{10}$ & $P_{2}$ \\
\hline Fengxiang & $T_{\text {minlas11t }}$ & $E_{8}$ & $T_{\min 3}$ & $T_{\text {last12 }}$ & $R_{5}$ & $P_{9}$ & $T_{\text {minlast12 }}$ & $T_{\max 5}$ & $T_{4 \mathrm{mid}}$ & $T_{5}$ \\
\hline Fufeng & $P_{7}$ & $P_{2}$ & $T_{\max 4}$ & $N_{\geq 37{ }^{\circ} \mathrm{C}}$ & $T_{\max 4 \operatorname{mid}}$ & $T_{\min 5}$ & $P_{\text {5late }}$ & $P_{10}$ & $T_{2}$ & $E_{5}$ \\
\hline Liquan & $P_{2}$ & $T_{\max 4}$ & $T_{10}$ & $T_{\text {min4late }}$ & $R_{8}$ & $T_{2}$ & $E_{10}$ & $T_{\min 4 \mathrm{mid}}$ & $T_{\text {max4late }}$ & $T_{\max }-T_{\min }$ \\
\hline Yongshou & $T_{2}$ & $T_{\text {max4late }}$ & $T_{10}$ & $P_{3}$ & $T_{\max 4}$ & $T_{\text {4late }}$ & $T_{\max 8}$ & $E_{7}$ & $P_{8}$ & $P_{5}$ \\
\hline Chunhua & $\mathrm{AT}_{20}$ & $T_{\max 4 \operatorname{mid}}$ & $P_{8}$ & $T_{\max 6}$ & $T_{10}$ & $T_{8}$ & $T_{\max 4}$ & $P_{\text {4late }}$ & $T_{7}$ & $\mathrm{AT}_{10}$ \\
\hline Qianxian & $T_{4}$ & $T_{\max 4}$ & $T_{\text {max4early }}$ & $T_{\text {max4late }}$ & $E_{4}$ & $T_{\max 4 \operatorname{mid}}$ & $T_{\text {min4late }}$ & $T_{4 \text { early }}$ & $P_{2}$ & $T_{10}$ \\
\hline Yaozhou & $W_{4 \mathrm{mid}}$ & $T_{\max 4 \operatorname{mid}}$ & $T_{\min 2}$ & $P_{8}$ & $P_{\text {5late }}$ & $P_{3}$ & $P_{\text {last11 }}$ & $P_{\text {4late }}$ & $P_{5}$ & $T_{1}$ \\
\hline Fuping & $W_{4 \text { early }}$ & $T_{2}$ & $P_{5}$ & $T_{\text {last12 }}$ & $T_{\max 7}$ & $E \mathrm{~T}_{10}$ & $N_{\geq 35^{\circ} \mathrm{C}}$ & $E_{7}$ & $P_{10}$ & $W_{4 \mathrm{mid}}$ \\
\hline
\end{tabular}

(zone III) decreased slightly, with a yield reduction ranging from -0.32 to $-0.01 \mathrm{t} / \mathrm{ha} 100 / \mathrm{a}$ (Table 3 ). Counties with significant yield reduction were Yanchang (zone I) and Hancheng (zone II), with yield reductions of -1.13 and 0.99 t/ha 100/a, respectively. Counties with significant yield increases were Fuping (zone II) and Qishan (zone III), with yield increases of 1.4 and $2.0 \mathrm{t} / \mathrm{ha} 100 / \mathrm{a}$, respectively. The remaining 15 base counties showed no or slightly increased yields, with yield increases ranging from 0.01 to $0.77 \mathrm{t} / \mathrm{ha} 100 /$ a. Under the RCP 8.5 scenario, the MY in Ansai, Luochuan, Binxian, Yongshou, Yaozhou, Yichuan, and Fuxian (zone I); Hancheng (zone II); and Fufeng and Liquan (zone III) decreased slightly, with yield reductions ranging from -0.84 to -0.05 t/ha 100/a. Counties with significant yield reduction were Chunhua and Xunyi (zone I), with yield reduction of 2.04 and -1.99 t/ha 100/a, respectively. Counties with significant yield increases were Baota and Longxian (zone I), Fuping (zone II), and Qishan (zone III), with yield increases of $1.17,1.13,2.15$, and $3.89 \mathrm{t} / \mathrm{ha} 100 / \mathrm{a}$, respectively. The remaining 12 base counties showed no or slightly increased yields, with yield increases ranging from 0.01 to 0.85 t/ha $100 /$ a.

Under the RCP4.5 and RCP 8.5 climate change scenarios, the prediction results for the 1990-2099 MY of apples showed that Ansai, Luochuan, Bingxian, Yongshou, Chunhua, and Yaozhou (zone I); Hancheng (zone II); and Fuping (zone III) all experienced yield reductions, while Baota, Changwu, Baishui, Longxian, and Fengxiang (zone I); Pucheng, Chengcheng, Heping, and Fuping (zone II); and Chencang and Qishan (zone III) all experienced yield increases. Fuping (zone II) and Qishan (zone III) both had significantly increased yields and therefore are the counties with yield increase potential associated with climate change. At the same time, yield changes under the RCP 4.5 scenario were relatively subtle and yield changes in many counties under the RCP 8.5 scenario were greater than those of the RCP 4.5 scenario. 
Table 3 Variation trends of MY from 1990 to 2099 in the 28 base counties of the apple-producing areas in Shaanxi province under the RCP4.5 and RCP 8.5 climate change scenarios. Units are t/ha 100/a

\begin{tabular}{|c|c|c|c|c|c|c|c|c|c|}
\hline Zone & Site & $\mathrm{RCP} 4.5$ & RCP8.5 & Site & RCP4.5 & RCP8.5 & Site & $\mathrm{RCP} 4.5$ & RCP8.5 \\
\hline \multirow[t]{7}{*}{ Zone I } & Ansai & -0.05 & -0.05 & Baota & 0.77 & 1.17 & Yanchuan & 0.01 & 0.02 \\
\hline & Yanchang & -1.13 & 0.58 & Yichuan & 0.01 & -0.51 & Changwu & 0.39 & 0.85 \\
\hline & Fuxian & 0.27 & -0.12 & Xunyi & 0.53 & -1.99 & Baishui & 0.46 & 0.68 \\
\hline & Luochuan & -0.15 & -0.08 & Yijun & -0.01 & 0.09 & Longxian & 0.02 & 1.13 \\
\hline & Qianyang & 0.25 & 0.55 & Binxian & -0.18 & -0.16 & Fengxiang & 0.07 & 0.01 \\
\hline & Yongshou & -0.12 & -0.13 & Chunhua & -0.32 & -2.04 & Qianxian & -0.08 & 0.56 \\
\hline & Yaozhou & -0.02 & -0.17 & & & & & & \\
\hline \multirow[t]{2}{*}{ Zone II } & Pucheng & 0.23 & 0.41 & Chengcheng & 0.15 & 0.32 & Heyang & 0.77 & 0.48 \\
\hline & Hancheng & -0.99 & -0.84 & Fuping & 1.4 & 2.15 & & & \\
\hline \multirow[t]{2}{*}{ Zone III } & Chencang & 0.27 & 0.39 & Qishan & 2.0 & 3.89 & Fufeng & -0.03 & -0.25 \\
\hline & Liquan & 0.2 & -0.15 & & & & & & \\
\hline
\end{tabular}

\subsubsection{Annual prediction analysis for fuzzy information granulation time windows}

During 1990-2019 (the reference period), 2020-2049, and 2050-2099 MY time window prediction periods, the maximum values for MY in the base counties under the RCP 4.5 scenario fell within the ranges of $0.10-2.77,-0.11-3.95$, and $-0.54-4.23 \mathrm{t} / \mathrm{ha}$, respectively. The mean values for these 3 time periods were $0.72,0.66$, and $0.75 \mathrm{t} / \mathrm{ha}$, respectively (Fig. 3a-c). Under the RCP 8.5 scenario, the maximum values fell within the ranges of $-0.18-3.41,-0.21-4.1$, and $-1.77-$ $4.84 \mathrm{t} / \mathrm{ha}$, respectively. The mean values for these 3 time periods were $0.96,0.78$, and $0.77 \mathrm{t} / \mathrm{ha}$, respectively. Under the RCP 4.5 scenario, the mean values for the base counties fell within the ranges of $-0.31-2.34,-0.53-2.48$, and $-0.73-$ $3.36 \mathrm{t} / \mathrm{ha}$, respectively. The mean values for the 3 time periods were $0.24,0.35$, and $0.5 \mathrm{t} / \mathrm{ha}$, respectively (Fig. $3 \mathrm{~d}-\mathrm{f}$ ). Under the RCP 8.5 scenario, the mean values fell within the ranges of $-0.81-2.1,-0.48-2.91$, and $-1.46-3.07 \mathrm{t} / \mathrm{ha}$, respectively. The mean values for the 3 time periods were $0.22,0.48$, and $0.51 \mathrm{t} / \mathrm{ha}$, respectively. Under the RCP 4.5 scenario, the minimum MY for the base counties fell within the ranges of $4.39-1.76,-1.22-2.32$, and $-3.28-2.29$ t/ha, respectively. The means for the 3 time periods were $-0.65,-0.01$, and 0.05 t/ha, respectively (Fig. $3 \mathrm{~g}-\mathrm{i}$ ). Under the RCP 8.5 scenario, the minimum values fell within the ranges of $-6.47-1.7$, 4.99-2.22, and $-1.87-2.23 \mathrm{t} / \mathrm{ha}$, respectively. The mean values for the 3 time periods were $-0.89,-0.46$, and $0.01 \mathrm{t}$ / ha, respectively.

\subsection{Prediction of yield per unit area}

Under the RCP 4.5 scenario, the unit yields in the base counties from 2000 to 2099 ranged from 1.75 to $27.08 \mathrm{t} / \mathrm{ha}$, with a mean unit yield of $14.14 \mathrm{t} / \mathrm{h}$. The unit yields for zone I ranged from 1.75 to $20.66 \mathrm{t} / \mathrm{ha}$, with a mean unit yield of $9.58 \mathrm{t} / \mathrm{ha}$. The unit yields for zone II ranged from 8.46 to $19.37 \mathrm{t} / \mathrm{ha}$, with a mean unit yield of $13.6 \mathrm{t} / \mathrm{ha}$. The unit yields for zone III ranged from 8.6 to $27.08 \mathrm{t} / \mathrm{ha}$, with a mean unit yield of $19.24 \mathrm{t} / \mathrm{ha}$. Under the RCP 8.5 scenario, the unit yields in the base counties from 2000 to 2099 ranged from 1.54 to $27.08 \mathrm{t} / \mathrm{ha}$, with a mean unit yield of $14.12 \mathrm{t} / \mathrm{ha}$. The unit yields for zone I ranged from 1.54 to $20.66 \mathrm{t} / \mathrm{ha}$, with a mean unit yield of $9.48 \mathrm{t} / \mathrm{ha}$. The unit yields for zone II ranged from 8.46 to $21.37 \mathrm{t} / \mathrm{ha}$, with a mean unit yield of $13.75 \mathrm{t} / \mathrm{ha}$. The unit yields for zone III ranged from 8.0 to $27.08 \mathrm{t} / \mathrm{ha}$, with a mean unit yield of $19.13 \mathrm{t} / \mathrm{ha}$.

\subsection{Analysis of predicted unit yield variation}

Under the RCP 4.5 and RCP 8.5 scenarios, the predictions of annual maximum and mean values for MY in the fuzzy information granulation time windows for the base counties showed that the maximum values from 2020 to 2049 and 2050 to 2099 were all higher than those of the reference period and the minimum values were all lower than the corresponding values during the reference period. Minimum value predictions showed that the maximum values and minimum values from 2020 to 2049 and 2050 to 2099 were all higher than those of the reference period. Under the RCP 4.5 scenario, when the 2020-2049 period was compared with the reference period, the variations of unit yield in zones I, II, and III ranged from -0.64 to $0.23 \mathrm{t} / \mathrm{ha},-1.44$ to $0.43 \mathrm{t} / \mathrm{ha}$, and -0.07 to $1.63 \mathrm{t} / \mathrm{ha}$, respectively (Fig. $4 \mathrm{a}$ ). When the 2050-2099 period was compared with the reference period, the variations of unit yield in zones I, II, and III ranged from -0.96 to $0.48 \mathrm{t} / \mathrm{ha}$, -1.18 to $0.71 \mathrm{t} / \mathrm{ha}$, and -0.01 to $1.85 \mathrm{t} / \mathrm{ha}$, respectively (Fig. $4 b)$. Under the RCP 8.5 scenario, when the 2020-2049 period was compared with the reference period, the variations of unit yield in zones I, II, and III ranged from -2.43 to $0.95 \mathrm{t} / \mathrm{ha}$, - 
Fig. 3 Decadal predictions of apple weather yields in the study area under the RCP4.5 scenario, including the maximum time window forecast for the years a 1990-2019, b 2020-2049, and c 2050-2099; the average time window forecast for the years $\mathbf{d}$ 1990-2019, e 2020-2049, and f 2050-2099; the minimum time window forecast for the years $\mathbf{g}$ 1990-2019, h 2020-2049, and i 2050-2099
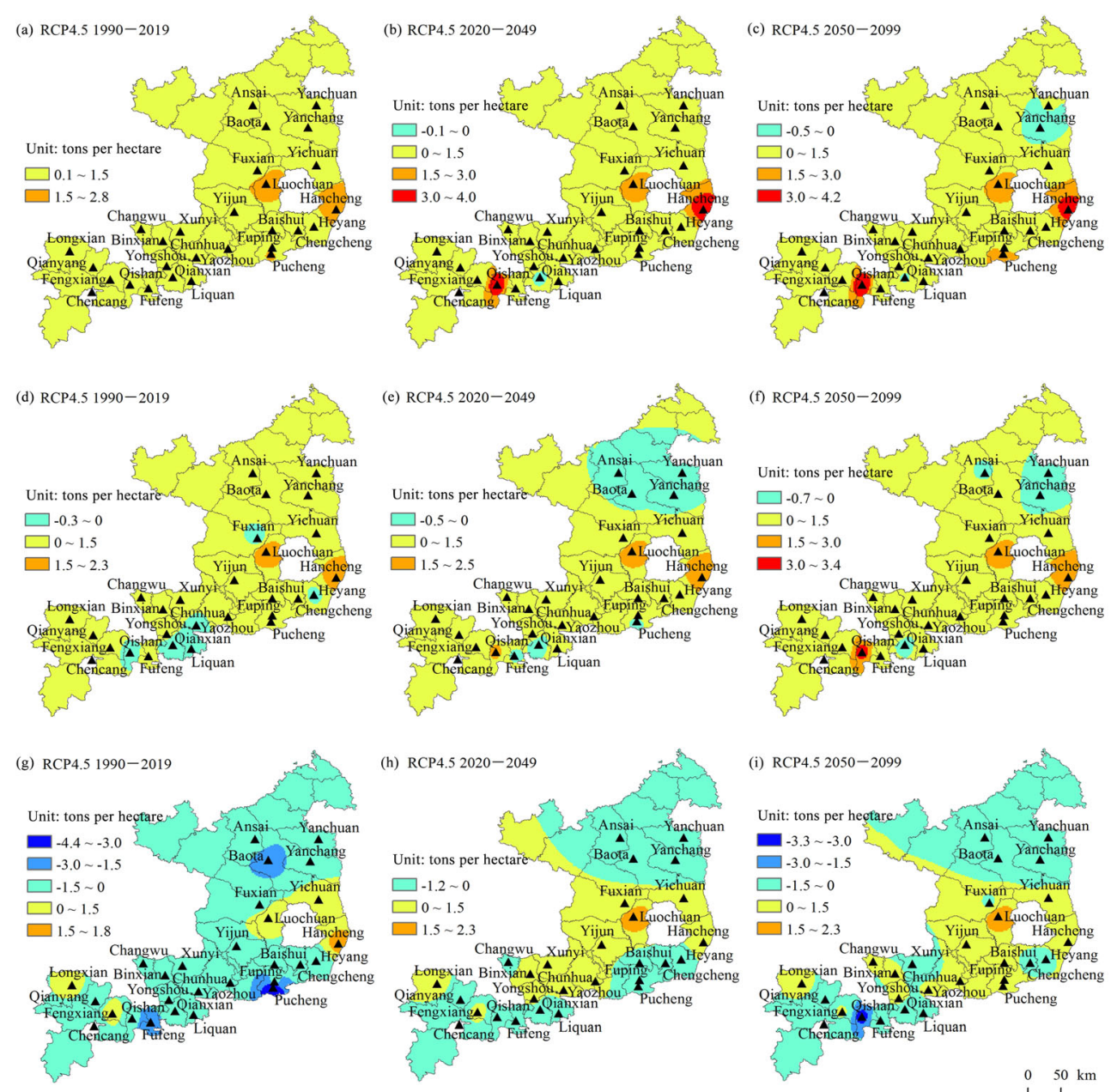

1.39 to $0.19 \mathrm{t} / \mathrm{ha}$, and -0.08 to $1.02 \mathrm{t} / \mathrm{ha}$, respectively (Fig. 4c). When the 2050-2099 period was compared with the reference period, the variations of unit yield in zones I, II, and III ranged from -2.12 to $1.06 \mathrm{t} / \mathrm{ha},-0.96$ to $1.18 \mathrm{t} / \mathrm{ha}$, and -0.16 to $2.78 \mathrm{t} /$ ha, respectively (Fig. $4 \mathrm{~d}$ ).

\section{Discussion}

Grey relational analysis of MY and climatic factors can determine the magnitude of the effects of different factors on yield during different years. The analysis results for the apple-producing base counties in Shaanxi province showed that temperature, precipitation, wind speed, evaporation, solar radiation, and active accumulated temperature are all climatic factors that are intimately associated with the MY of apples in this region. When the time periods that were affected by the aforementioned factors were coupled with the characteristics of apple growth stages for analysis, the results showed that the flowering and pollination stages are important meteorologically sensitive stages. The meteorological factors $T_{4}, T_{\max 4}, W_{4}, E_{4}$, and $R_{4}$ have significant effects on the start time and duration of flowering, pollination, and fertilization. During the stage when young fruit cells are proliferating, $P_{5}$ significantly promotes the increase in the number of young apple cells. At the same time, since $P_{5}$ is conducive for cell division, this factor proves to be a physiological basis for apple yield. $T_{\max 6}$ and $E_{7}$ are beneficial to the growth and expansion of apple fruits, while $P_{8}$ promotes an increase in cell volume, thereby increasing the weight of single fruits. $T_{2}, T_{\min 2}$, and $P_{2}$ have significant effects on MY. During the coloring and maturation phase in apples, $T_{10}$ also has significant effects on MY. $\mathrm{AT}_{10}$ and $\mathrm{AT}_{20}$ appear during the tree growth season and fruit growth phase and significantly influence the MY of apples.

In this study, we systematically analyzed the combination of climatic factors that affects MY in the apple-producing base counties of China's Loess Plateau. We refined the climatic factors that affect apple yield determined by Fujisawa and Kobayashi (2011) to 10-day and monthly factors. Our research results on climatic factors are consistent with those of a previous study by Eccel et al. (2009), with both studies indicating that spring climatic factors are more important for yield than other seasonal factors. In this study, the meteorological factors that impact yield are more comprehensive and provide a more complete and reliable explanation for 
Fig. 4 Predicted apple unit yields in the study area for the years a 2020-2049 and b 2050-2099; c under the RCP4.5 scenario for the years 2020-2049 and d under the RCP8.5 scenario for the years 2050-2099
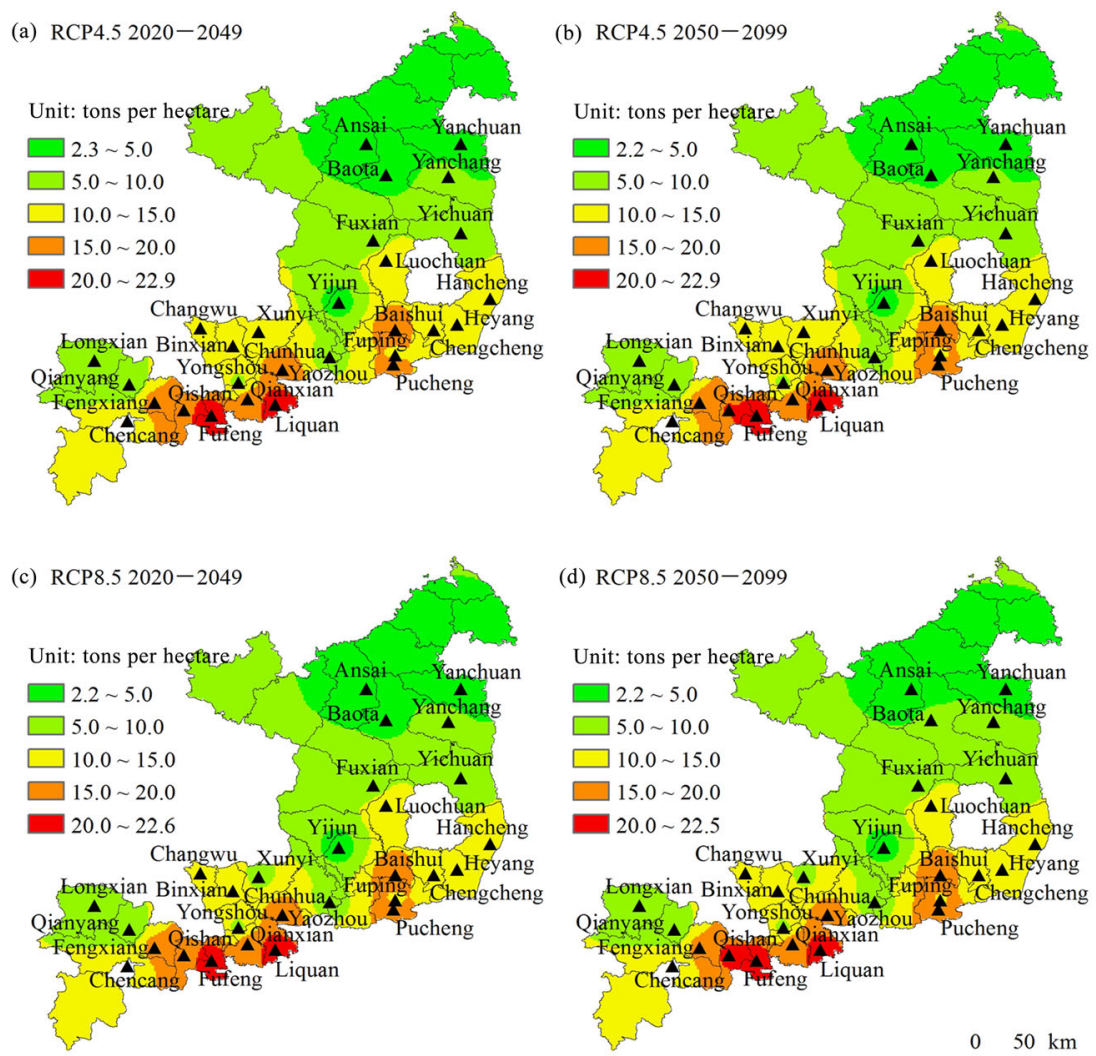

formation mechanisms of fruit yield than the studies of Aggelopoulou et al. (2011) and Papageorgiou et al. (2013), both of which only used the distribution and density of flowering in spring apple trees to predict yield.

When studying the responses of apple tree yield to climate change, many meteorological factors were taken as driver variables and combined using non-linear relationships in order to analyze the variation trends in MY and unit yield in appleproducing base counties in Northwest China. An SVM was utilized for the prediction of MY in 93\% (26 of 28) of the base counties in Shaanxi province under the 2 climate change scenarios of RCP 4.5 and RCP 8.5. The predicted values were all extremely close to the MY, and the SVM mean predictive performances all exceeded $82 \%$, with an error range of 16$18 \%$. Therefore, the overall performance of the SVM was good and demonstrates that it is feasible to employ SVM methods for the prediction of apple yield in Shaanxi province. The prediction precision for the MY of apples under the RCP 8.5 scenario was $2 \%$ higher than the precision of RCP 4.5 , indicating better prediction results. However, under the RCP 4.5 scenario, the differences between the predicted values for Xunyi and Qishan (7\%) were more significant; under the RCP 8.5 scenario, the differences between the predicted value for Yijun and Qishan (7\%) were more significant. Thus, the yield predictions for Xunyi, Yijun, and Qishan may require other methods.
Therefore, taking into account the effects of future climate change, we recommend that developmental policies for the apple industry in China include the expansion of apple cultivation areas and industry scale in base counties showing clear trends of increased apple yield. Importantly, apple crops in base counties with significant meteorological disaster potential can be converted to varieties that have a strong resistance to disaster, while base counties with significant yield reduction trends should focus on improving quality and efficiency in order to enhance economic benefits.

As a final caveat, we only used one RCM outputs and one realization only as the data source due to data availability in the present. As widely known, multimodel ensembles are very important to address and reduce the uncertainties in future climate change projections. Recently, multi-GCM-driven RCM and multi-GCM-driven multi-RCM simulations have been carried out or planned over the region (Gao et al. 2018). We will conduct further studies based on these simulations soon after the data become available for the community.

\section{Conclusions}

Analysis of the major climatic factors showed that the effects of temperature, wind speed, precipitation, evaporation, and active accumulated temperature on MY decrease in that order. 
Among the 10-day and monthly climatic factors that affect the MY of apples, the frequency of climate resources is greater than that of meteorological disasters. There are more and broader climate resource factors compared to disaster factors that affect MY. Spring climatic conditions are more important for MY than the climatic conditions of the other 3 seasons.

The prediction results showed that under the 2 climate change scenarios (RCP4.5 and RCP 8.5) extending through the year 2099, the positive effects of climate change on the MY of apples in Shaanxi province proved to be greater than the negative effects. The variation range for the MY of apples from 2020 to 2049 and 2050 to 2099 will be higher than that of the reference period (1990-2019). Under future climate change scenarios, fluctuations in the MY of apples will be greater and annual uncertainty in MY will become more significant. When the period 2050-2099 was compared with 2020-2049, fluctuations and uncertainty were found to be enhanced.

Acknowledgments We thank Professor Gao Xuejie for the climate scenario data sets provided by the Chinese National Climate Centers.

\author{
Authors' contributions Conceptualization: JPG, MRL. \\ Formal analysis: MRL. \\ Methodology: MRL, CDX. \\ Data curation: CDX, MRL. \\ Software: CDX, SLT. \\ Validation: JPG, JQH, JKL. \\ Resources: JKL. \\ Writing — original draft: MRL, CRM. \\ Writing — review and editing: JQH.
}

Funding information This work was supported by the Innovative Postgraduate Training Program of the Department of Education of Jiangsu Province, China (Grant No. CXLX13-500).

Data availability All relevant data are within the paper and its Supporting Information files.

\section{Compliance with ethical standards}

Competing interests The authors declare that they have no competing interests.

Open Access This article is distributed under the terms of the Creative Commons Attribution 4.0 International License (http:// creativecommons.org/licenses/by/4.0/), which permits unrestricted use, distribution, and reproduction in any medium, provided you give appropriate credit to the original author(s) and the source, provide a link to the Creative Commons license, and indicate if changes were made.

\section{References}

Aggelopoulou AD, Bochtis D, Fountas S, Swain KC, Gemtos TA, Nanos GD (2011) Yield prediction in apple orchards based on image processing. Precis Agric 12(3):448-456
Angstrom A (1924) Solar and terrestrial radiation. Report to the international commission for solar research on actinometric investigations of solar and atmospheric radiation. Q J R Meteorol Soc 50(210): $121-126$

Cao M-X (2007) Research on grey relational analysis model and its application. Nanjing Aerospace University, Nanjing

Chu Zheng GJ-P, Zhao J-F (2017) Impacts of future climate change on agroclimatic resources in Northeast China. J Geogr Sci 27(9):10441058

Corinna C, Vladimir V (1995) Support-vector network. Mach Learn 20(3):273-297

Deng J-L (1982) Grey control system. J Huazhong Institute Technol 3: $11-20$

Deng J-1 (1985) Grey system and agriculture. J Shanxi Agric Sci 5:34-37

Deng J-1 (2002) Gray theory basis. Huazhong university of science and technology press, Wuhan

Ding Y, Ren G-Y, Shi G (2006) National assessment report of climate change (I): climate change in China and its future trend. Adv Clim Chang Res 03(12):1-5

Eccel E, Rea R, Caffarra A, Crisci A (2009) Risk of spring frost to apple production under future climate scenarios: the role of phenological acclimation. Int J Biometeorol 53(3):273-286

Fang S-B (2011) Exploration of method for discrimination between trend crop yield and climatic fluctuant yield. J Nat Dis 20(6):13-20

FAOSTAT (2018) Food balance sheets. [Internet]. Available from: http:// www.fao.org/faostat/en/\#data/FBS.2018.7.3

Feng Y, Cui N-B, Gong D-Z, Wei X-P, Wang J-Q (2015) Prediction model of reference crop evapotranspiration based on extreme learning machine. Trans Chin Soc Agric Eng 31(Supp.1:153-160. https://doi.org/10.3969/j.issn.1002-6819.2015.z1.018

Flato G, Marotzke J, Abiodun B, Braconnot P, Chou SC, Collins W, Cox P, Driouech F, Emori S, Eyring V, Forest C, Gleckler P, Guilyardi E, Jakob C, Kattsov V, Reason C, Rummukainen M (2013) Evaluation of Climate Models. In: Stocker TF, Qin D, Plattner G-K, Tignor M, Allen SK, Boschung J, Nauels A, Xia Y, Bex V, Midgley PM (eds) Climate change 2013: the physical science basis. Contribution of Working Group I to the Fifth Assessment Report of the Intergovernmental Panel on Climate Change. Cambridge University Press, Cambridge and New York

Fujisawa M, Kobayashi K (2011) Climate change adaptation practices of apple growers in Nagano, Japan. Mitig Adapt Strateg Glob Chang 16(8):865-877

Gao X-J, Giorgi F (2017) Use of the RegCM system over East Asia: review and perspectives. Engineering. 3(5):766-772

Gao XJ, Wu J, Shi Y, Wu J, Han ZY, Zhang DF, Tong Y, Li RK, Xu Y, Giorgi F (2018) Future changes of thermal comfort conditions over China based on multi-RegCM4 simulations. Atmos Ocean Sci Lett 11(4):291-299. https://doi.org/10.1080/16742834.2018.1471578

Giorgi F, Coppola E, Solmon F, Mariotti L, Sylla MB, Bi X, Elguindi N, Diro GT, Nair V, Giuliani G, Turuncoglu UU, Cozzini S, Güttler I, O'Brien TA, Tawfik AB, Shalaby A, Zakey AS, Steiner AL, Stordal F, Sloan LC, Brankovic C (2012) RegCM4: model description and preliminary tests over multiple CORDEX domains. Clim Res 52:729. https://doi.org/10.3354/cr01018

Guo H-Y, Zhao J-P, Suo A-N, Yang X-G, Huang B, Ges J-P (2006) Response of agricultural phenospectrum to global climate change in Loess Plateau of east Gansu province. J Nat Resourc 21(4):608614

Li X-M (2013) Agricultural climate resources and regionalization in Shaanxi Province based on GIS. Shaanxi Science and Technology Press, Xian

Li X-M, Bai Q-F, Zhu L (2011) The influence of climate change on suitability of Shaanxi apple growth. J Appl Meteorol Sci 22(2): 241-248 
Li Z-X, Nie J-Y, Li J, Xu G-F, Li H-F, Yan Z (2014) Analysis of apple industry in China and recommendations for future development. China Fruits 5:81-84

National Bureau of Statistics of China (2016) China rural statistical yearbook. China Statistics Press, Beijing

Papageorgiou EI, Aggelopoulou KD, Gemtos TA, Nanos GD (2013) Yield prediction in apples using fuzzy cognitive map learning approach. Comput Electron Agric 91(2):19-29

Pu J-Y, Yao X-Y, Yao X-H, Xu Y-P, Wang W-T (2008) Impacts of climate warming on phonological period and growth of apple tree in Loess Plateau of Gansu province. Chin J Agrometeorol 29(2):181-186

Qu Z-J, Liu R-F, Guo Z-X, Wang J-H, Liu L, Chai Q (2013) Study of risk assessment and prediction of apple blooming freezing injury in Shaanxi Province. J Nat Dis 22(1):219-225

Sun Y-G, Dang Y-G (2008) Improvement on grey T's correlation degree. Syst Eng Theor Pract 28(4):135-139

Wan Z-W, Xu Y-P, Yao X-L, Xu Y-K (2016) Impact of climate change on peach yield at Tianshui, Gansu in recent 30 years. Arid Land Geography 39(4):738-746

Wang J-H (2012) Atlas of climate suitability and meteorological disaster risk zoning of main fruit trees in Shaanxi Province. Shaanxi Science and Technology Press, Xian

Wang X-C, Shi F, Yu L, Li Y (2013) Neural network 43 case studies. Beijing University of Aeronautics \& Astronautics Press, Beijing

William HP, Saul AT, William TV, Brian PF (2007) Numerical recipes: the art of scientific computing, 3rd edn. Cambridge University Press, New York

Xin X-G, Wu T-W, Zhang J (2013) Introduction of CMIP5 experiments carried out with the climate system models of Beijing Climate Center. Adv Clim Chang Res 4(1). https://doi.org/10.3724/SP.J. 1248.2013.041

Xin C-Y, Xiong S-R, Wang L-P, Yuan Y-P, Xu Y-P (2015) Analysis of drought and flood change trend in 33 years and its effect on fruit tree production in Maijiqu in Gansu province. Chin Agric Sci Bull 31(16):233-240

Xu Y-P, Yao X-H, Liu X-Q, Ma J, Wang H-B (2015) Impact assessment of the Tianshui apricot yield under the climate resources change background in recent 30 a. Arid Land Geography. 38(4):684-691
Yang F-Y, Zhang Y-S, Li W-K, Lyu H-Q, Luo J-M (2017) Chilling damage comprehensive assessment methods for rice. Chin J Appl Ecol 28(10):3281-3288

Zadeh LA (1979) Fuzzy sets and information granulation.advances in fuzzy set theory and applications. North-Holland Publishing, Amsterdam

Zadeh LA (1997) Towards a theory of fuzzy information granulation and its centrality in human reasoning and fuzzy logic. Fuzzy Sets Syst 90(90):111-127

Zadeh LA (1998) Some reflections on soft computing,granular computing and their roles in the conception,design and utilization of information/intelligent systems. Soft Comput 2(1):23-25

Zhai H, Zhao Z-Y, Wang Z-Q, Shu H-R (2005) Analysis of the development trend of the world apple industry. J Fruit Sci 22(1):44-50

Zhang X-C (2005) Spatial downscaling of global climate model output for site-specific assessment of crop production and soil erosion. Agric For Meteorol 135(1):215-229

Zhang X-C (2007) A comparison of explicit and implicit spatial downscaling of GCM output for soil erosion and crop production assessments. Clim Chang 84(3-4):337-363

Zhang S-H, Li J, Wang X-C, Wang Y-L (2011) Modeling the changes of yield and deep soil water in apple orchards in Weibei rainfed highland. Acta Ecol Sin 31(13):3767-3777

Zhao J-F, Pu F-Y, Yan W-X, Xu J-W, Li N, Pan Z-H et al (2017) Identifying the effects of meteorological variables on spring wheat potential yield in Inner Mongolia based on APSIM model. Chin J Ecol 36(03):757-765

Zhou T-J, X-1 C, Dong L, Bo W, Man W-M, Zhang L-X, Lin H-P, Yao JC, Song F-F, Zhao C-B (2014a) Chinese contribution to CMIP5: an overview of five Chinese models' performances. J Meteorol Res 28(4):481-509. https://doi.org/10.1007/s13351-014-4001-y

Zhou G-S, Guo J-P, Huo Z-G (2014b) Chinese agriculture responds to climate change. China Meteorological Press, Beijing

Publisher's note Springer Nature remains neutral with regard to jurisdictional claims in published maps and institutional affiliations. 